\title{
El cómic de no-ficción como fuente para el estudio de los conflictos bélicos: Crónicas de Jerusalén
}

\author{
Salomé Sola Morales \\ Universidad de Santiago de Chile \\ salome.sola@usach.cl \\ Gonzalo Barroso PeÑa \\ Universidad Nacional de Educación a Distancia \\ gonzbarroso@gmail.com
}

Recibido: 26 de abril de 2014

Aceptado: 1 de julio de 2014

\section{Resumen}

En el presente artículo se cuestiona cuáles son los aportes que el cómic, como género híbrido, puede tener en la investigación histórica del conflicto bélico árabe-israelí. Para ello, se ha realizado un análisis de la obra gráfica Crónicas de Jerusalén de Guy Delisle en relación al tratamiento de tres subtemas: la configuración del contexto de referencia y la pretensión de neutralidad; el uso de fuentes y la construcción del relato; y la prospectiva del conflicto. La principal conclusión a la que hemos llegado es que este cómic de no-ficción es una fuente complementaria de gran utilidad para la compresión y el estudio de este conflicto bélico, que todavía hoy no encuentra solución.

Palabras clave: cómic; conflicto árabe-israelí; medios de comunicación; fuentes históricas.

\section{The nonfiction comic as a source for the study of armed conflicts: Chronicles of Jerusalem}

\begin{abstract}
This paper questions which contributions can have a comic, as an hybrid genre, on the historical research of the Arab-Israeli conflict. Specifically, we analyze the discourse and the historical content of the comic book Jerusalem: Chronicles from the Holy City, by Guy Delisle, in relation to three topics: first, the configuration of the context of reference and the pretense of neutrality; second, the use of sources and the construction of the story; and third, the prospective of the conflict. The main conclusion we have reached is that this non-fiction comic is a very useful complementary source for historical research and comprehension of this conflict that still no have solution.
\end{abstract}

Key words: historical comic; Arab-Israeli conflict; media; historical sources.

\section{Referencia normalizada:}

Sola Morales, S. y Barroso Peña, G. (2014) El cómic de no-ficción como fuente para el estudio de los conflictos bélicos: Crónicas de Jerusalén. Historia y Comunicación Social. Vol. 19. Páginas 231-248.

Sumario: 1. Introducción. 2. Objetivo, hipótesis y metodología. 3. El cómic como fuente para la investigación histórica. 4. Análisis de Crónicas de Jerusalén. 4.1. La configuración del contexto y la pretensión de neutralidad. 4.2. El uso de fuentes y la construcción del relato. 4.3. La prospectiva del conflicto. 5. Conclusiones. 6. Referencias bibliográficas. 


\section{Introducción}

La reciente investigación sobre la cobertura de conflictos bélicos en los medios de comunicación (Bonilla y Tamayo, 2007; Sierra y Contreras, 2004; Rodrigo Alsina, 2001; Montanari, 2000) ha puesto de manifiesto las limitaciones que los discursos mediáticos acerca de conflictos bélicos traen consigo, ya que muchas veces se encuentran supeditados al discurso oficial (García y Pereira, 2000). Y, precisamente por eso, tienen grandes dificultades para presentar a las audiencias un discurso que profundice en el contexto, analice las causas, antecedentes, motivos o consecuencias de los conflictos presentes, tareas generalmente relegadas a la investigación académica.

Si bien es cierto que los profesionales de la comunicación (reporteros de guerra o enviados especiales) sufren grandes dificultades en el desempeño de su trabajo (Albarrán, 1999; Serrano, 2005), por desgracia, lo cierto es que la dinámica mediática tiende a la construcción de relatos simplificadores (Barón y Valencia, 2001), donde el enfrentamiento y la polarización entre "buenos" y "malos", o el morbo y la violencia se convierten en los principales ingredientes. La consecuencia principal de esta retórica bélica, que privilegia "el drama, la tragedia, la novedad la espectacularidad, el antagonismo y el heroísmo" (Bonilla y Tamayo, 2007: 215) es "el extrañamiento total del 'otro"' (Serrato, 2004: 188), sea éste el enemigo o la víctima del conflicto en cuestión.

En este contexto, vale preguntarse si la realidad representada en los medios es acorde o justa con los protagonistas de los conflictos o se reduce a un simulacro (Baudrillard, 1994; Correa, 2001) teatralización o espectacularización (Debord, 1991; Abello, 2001) -más o menos amable- que termina generando mayor cuota de pantalla. A pesar de todo ello, y también a las críticas que los discursos mediáticos reciben constantemente, las noticias de prensa, los informativos televisivos o las películas cinematográficas son consideradas fuentes ineludibles para la investigación histórica (Alía Miranda, 2008; Ferro, 1980). Está completamente aceptado que ofrecen información valiosa y una mirada diferente sobre procesos históricos o conflictos bélicos tanto del pasado como del presente.

Pero ¿acaso puede un cómic aportar elementos válidos para una investigación histórica? En este sentido, este artículo explora la posibilidad de tomar como referencia este tipo de fuentes alternativas que, quizás por su formato han sido menos investigadas, pero no por ello tienen por qué tener menor relevancia. Quizás estos documentos gráficos puedan aportar elementos clave para comprender la realidad de un conflicto como el árabe-israelí y puedan mostrar la complejidad de una forma diversa, menos ideologizada y más atractiva para el ciudadano común.

La imperante cultura mediática en la que nos encontramos inmersos pone de manifiesto que los relatos que circulan en los medios de comunicación y otros productos masivos tales como la fotografía, el cine e, incluso, los cómics y novelas gráficas pueden aportar elementos complementarios para la investigación histórica. Esta idea 
es concretamente la que marca la pauta de esta investigación. Ya que estas fuentes alternativas son de gran relevancia para la creación de imaginarios, valores y opiniones compartidas acerca de los conflictos bélicos del público general-que difícilmente recurre a los libros de historia para informarse del presente-, es preciso investigarlas en profundidad.

\section{Objetivo, hipótesis y metodología}

El principal objetivo de este artículo es cuestionar si una fuente como el cómic puede aportar a la investigación histórica y a la comprensión de fenómenos globales y complejos del presente. Para dicho fin hemos tomado la obra gráfica Crónicas de Jerusalén y mediante su análisis pretendemos cuestionar nuestra hipótesis que exponemos en los siguientes términos: el cómic Crónicas de Jerusalén es una fuente válida para el estudio del conflicto entre Israel y Palestina, ya que presenta un relato que arroja luz sobre un proceso histórico.

En cuanto a la metodología seleccionada, nuestra aproximación es de tipo cualitativo y se fundamenta en una crítica de la fuente, interna y externa (Alía Miranda, 2008). Analizaremos la obra gráfica Crónicas de Jerusalem y cuestionaremos cuál es el tratamiento de los siguientes tres subtemas desde la perspectiva del análisis de contenido. Los tópicos objeto de nuestro análisis serán: a) la configuración del contexto y la pretensión de neutralidad; b) el uso de fuentes y la construcción del relato; y c) la prospectiva del conflicto.

\section{El cómic como fuente para la investigación histórica}

Si bien es cierto que en las últimas décadas se han realizado aproximaciones al uso de la imagen -iconográfica y audiovisual- como fuente histórica (Ankersmit, 2002; Burke, 2001) lo cierto es que todavía hoy la literatura científica acerca del valor historiográfico del cómic es escasa (Da Silva, 2012; Flores, 2007; Gual Boronat, 2011). Así pues, nos encontramos ante un campo de investigación poco explorado desde la Historia. En este sentido, han sido los campos de la Psicología, la Sociología y, sobre todo, los Estudios de Comunicación los que mayor énfasis han prestado a los relatos gráficos (Del Río, 1984; Fernández y Poblete, 2009; Gasca y Gubern, 1991; Gubern, 1974; Massota, 1982; Melero Domingo, 2012).

Aunque generalmente se usan como sinónimas diferentes nociones como cómic, historieta, tebeo o novela gráfica, el mejor término en castellano -según Vergara (2009) - es el de cómic, ya que se aleja del matiz infantil o humorístico que se asocia al tebeo, por ejemplo. En este contexto, consideramos que el concepto de cómic es más apropiado que el de historieta, considerada relato menor (Melero Domingo, 2012). El término cómic nos permite definir bien este producto gráfico, fruto de la cultura 
de masas (Gubern, 1997), que cada día tiene mayor vigencia y reconocimiento, y se aleja más del mero entretenimiento (Barbieri, 1993). En 1992 Art Spielgeman recibió el Premio Pulitzer por su obra Maus, sobre el Holocausto judío, mientras que en 2010 Joe Sacco fue premiado por la Fundación Fertel por su Notas al pie de Gaza, que se considera a medio camino entre el cómic y el reportaje periodístico.

En palabras de Serrato, el cómic es un género "plástico-narrativo eminentemente massmediatico, nacido en los últimos años del s. XIX y tan ligado al kitsch como a la cultura pop, tan 'infantil' como subversivo, tan alienante como underground, tan oficialista como alternativo" (Serrato, 2004: 196). No obstante, es difícil catalogar o definir un género que en sus años de historia ha transitado entre la ficción y la no-ficción, la fantasía y los hechos reales o históricos. De hecho, se podría hablar de un subgénero llamado "fact-based comics" (Witek, 1989) o cómics históricos, que son de no-ficción y que se generan en condiciones sociales determinadas y que se asemejan bastante a los relatos periodísticos (Melero Domingo, 2012).

Estos cómics basados en hechos reales están basados en investigaciones previas y utilizan fuentes diversas, motivo por el que, sin duda, pueden aportar a la investigación histórica. Precisamente, esta conexión con la realidad es una de las características que los convierten en recursos históricos de gran utilidad para el estudio de las Ciencias Sociales o para ser utilizados en el ámbito didáctico (Gutiérrez Párraga, 2006; Mahecha Arango, 2012).

Si bien podría pensarse que un cómic no es el mejor medio de expresión para documentarse acerca de un conflicto bélico como es el de Israel y Palestina, consideramos con Pizarroso Quintero (2004: 20) que "la historia de los conflictos armados en el siglo XX no se puede entender sin detenerse en sus aspectos comunicativos". Precisamente por eso, el cómic en tanto producto de la cultura masiva o discurso masivo "resulta adecuado para leer nuestras sociedades postmodernas" (Serrato, 2004: 222).

\section{Análisis de Crónicas de Jerusalén}

Escrita y dibujada en 2011 por Guy Delisle (Québec, 1966), esta novela gráfica cuenta la experiencia del dibujante canadiense en tierras palestinas entre agosto de 2008 y julio de 2009. Durante ese tiempo, se dedicó a extraer los sinsentidos de un tema tan complejo como el que lleva azotando a esta zona de Oriente Próximo desde 1948. Valga hacer notar que Delisle no ha sido el único en llevar al cómic el problema palestino-israelí. Por poner algunos ejemplos, citaremos las siguientes obras: Una judia americana perdida en Israel de Sarah Glidden (2011), Jerusalén. Un retrato de familia de Boaz Yakin y Nick Bertozzi (2013), Notas al pie de Gaza de Joe Sacco (2010), KO en Tel Aviv de Asaf Hanuka (2013), Mezek de Yann y André Juillard (2012), o Saltar el Muro de Maximilien Le Roy (2011). Todas ellas, con historias más o menos alejadas de la realidad, también han tratado el mismo conflicto. 
Concretamente en Crónicas de Jerusalén, Delisle acompaña a su pareja, que trabaja para Médicos Sin Fronteras entre Cisjordania y la Franja de Gaza, y aprovecha para trasladar el conflicto a la viñeta de manera que el lector pueda comprenderlo de una manera más gráfica. A lo largo de 326 páginas y unas 2.000 viñetas, el dibujante canadiense nos relata sus propias vivencias en tierras palestinas e israelíes para comprender mejor el origen y desarrollo de un conflicto que era parte de la Guerra Fría, pero que aún hoy día sigue sin tener solución (Portilla Gómez, 2007).

\subsection{La configuración del contexto y la pretensión de neutralidad}

Uno de los puntos tangenciales de esta obra gráfica es la labor de contextualización del conflicto que realiza su autor al mostrar un retrato de las religiones que conviven en el Estado de Israel. Esta panorámica, no obstante, no es una retrospectiva o vuelta al pasado, sino que se trata de una aproximación al presente desde la propia vivencia, ya que el autor narra su propia experiencia vivida desde un marcado tono auto-biográfico. La narración del conflicto en primera persona nos aleja de un acercamiento referencial o distante de lo que ocurre y, por el contrario, nos acerca a la vida cotidiana misma.

En este sentido, la mirada de Guy Delisle se parece más a la de un antropólogo que rescata lo anecdótico, lo cómico de las situaciones que vive, que a la de un reportero en busca de la noticia, como sí podría ser el caso de otros cómics también basados en hechos reales, como el de Joe Sacco Notas al pie de Gaza (Melero Domingo, 2012). Por eso, más que tratarse de un reportaje periodístico, consideramos que Crónicas de Jerusalén ofrece un estudio detallado de las costumbres, creencias, tradiciones e intereses del conflicto. Este retrato puede servir para comprenderlo mejor o convertirse en una aproximación para los foráneos que visiten Israel y los territorios palestinos.

Si bien nos encontramos ante un relato eminentemente subjetivo, ya que la historia que cuenta y dibuja Delisle parte de su experiencia personal, creemos que la obra constituye una fuente totalmente válida para el estudio de este conflicto bélico. En este sentido, aunque el autor no pretenda alcanzar la objetividad que se le presume al historiador, sí que son loables sus esfuerzos por mantenerse imparcial ante el problema palestino-israelí, algo que podemos observar desde el empleo de colores neutros, que oscilan entre una amplia gama de grises y sepias.

Precisamente, el tema de la religión es uno de los que más llama la atención al autor en su relato y el que nos permite evidenciar su pretensión de neutralidad. En gran parte, esto tiene que ver con el hecho de que la experiencia de Delisle sea contada desde la ciudad de Jerusalén, donde conviven musulmanes, judíos y cristianos. Sin duda, el componente religioso es una de las principales causas que explica el conflicto árabe-israelí. Es más, en los últimos años, se ha producido un claro avance de los fundamentalismos religiosos, en detrimento de los nacionalismos, como base ideológica de israelíes y palestinos (Álvarez, 2006). Aunque en muchas ocasiones el laicismo del autor le lleve a criticar en exceso ciertas situaciones, sobre todo referidas a colectivos cristianos, lo cierto es que hace un completo recorrido sobre las 
tradiciones y costumbres de las tres religiones sin tomar partido por ninguno de los colectivos.

En cierta medida, cuando Delisle no se posiciona a favor de ningún grupo religioso está adquiriendo un criterio objetivo, lo cual le confiere enorme veracidad. Su punto de vista es el de un mero observador de la realidad, y como tal, podemos considerarlo como una fuente fiable una investigación científica. De hecho, cuando trata festividades como el Sabbat, el Ramadán, el Yom Kippur, el Purim o la Pascua Judía, Delisle adopta un papel que lo sitúa al margen de lo que sucede. Quizás, en algunas ocasiones, se podría pensar que esta lejanía con la que trata el tema de la religión pueda llegar a convertirse en superficialidad. Pero lo cierto es que su tarea como novelista gráfico no consiste en ahondar en las causas históricas del enfrentamiento religioso que se da en Israel y Palestina, sino en mostrar cómo afectan estas diferencias en el día a día de cada comunidad. Lo cual no obstante, aporta datos relevantes para comprender el conflicto bélico en toda su complejidad.

Una de las críticas más acertadas y que más llama la atención es la que realiza sobre el papel del colectivo cristiano en el conflicto árabe-israelí. Se trata de una opinión que Delisle expresa a raíz de una noticia sobre una pelea ocurrida en el Santo Sepulcro entre sacerdotes de diferentes comunidades cristianas. La crítica consiste en que deberían ser los cristianos los que dieran ejemplo para acabar con la violencia que enfrenta a palestinos e israelíes, pero ni ellos mismos son capaces de superar sus diferencias de manera pacífica. En este caso, el autor no parece haber tenido presente que cerca de un $10 \%$ de la población palestina profesa la fe cristiana (Vilar, 2003) y es parte activa del conflicto.

Otro tema que también es tratado con mucho acierto por parte de Delisle es la mercantilización de los monumentos cristianos, como el citado Santo Sepulcro, convertidos en productos para el turismo cultural de masas (Toselli, 2006), lo cual nos puede indicar hacia donde se dirigen ciertos intereses de la cristiandad en el siglo XXI. En esta misma línea, sitúa a la religión judía, cuando muestra el negocio de merchandising que hay montado tras la kipá, por ejemplo.

Sin duda, el colectivo religioso al que mayor dedicación le concede Delisle en Crónicas de Jerusalén es al judío. Es más, la única costumbre religiosa que a lo largo del cómic el autor vive desde dentro, y por tanto nos puede contar de una forma más detallada y auténtica, es la participación en una kabalat sabbat, la típica comida de recepción del Sabbat. En esas viñetas se tratan temas como los problemas que históricamente han tenido los judíos para llegar a tierras israelíes, el cumplimiento de las estrictas normas en torno a la celebración del Sabbat o los prejuicios que tiene la población judía respecto a los barrios árabes de Jerusalén. A lo largo de todo el libro, el autor hace una observación bastante exhaustiva del comportamiento de este colectivo durante sus festividades.

Aunque en algunas ocasiones se quede en la anécdota, como por ejemplo cuando trata el Purim, lo cierto es que, a través de la celebración del Sabbat, consigue realizar un análisis de la sociedad israelí digno de un analista (Fig. 1). Precisamente este tipo 
de ejemplos, nos ayuda a comprender los diferentes modos que existen de entender el alcance del conflicto en ciudades como Jerusalén o Tel-Aviv. Mientras en la primera conducir un coche en Sabbat por determinados barrios, como el de Mea Shearim, puede conllevar reacciones violentas por parte de la población; en la segunda, la actividad urbana no se detiene por la celebración de una festividad religiosa (Fig. 2).

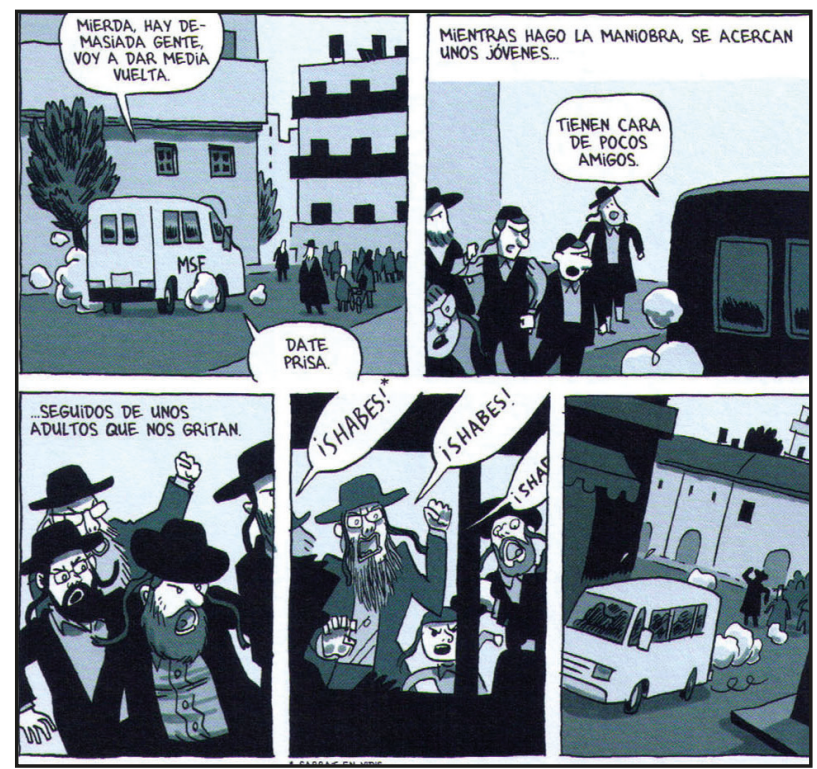

Fig. 1. El Sabbat en un barrio ultraortodoxo.

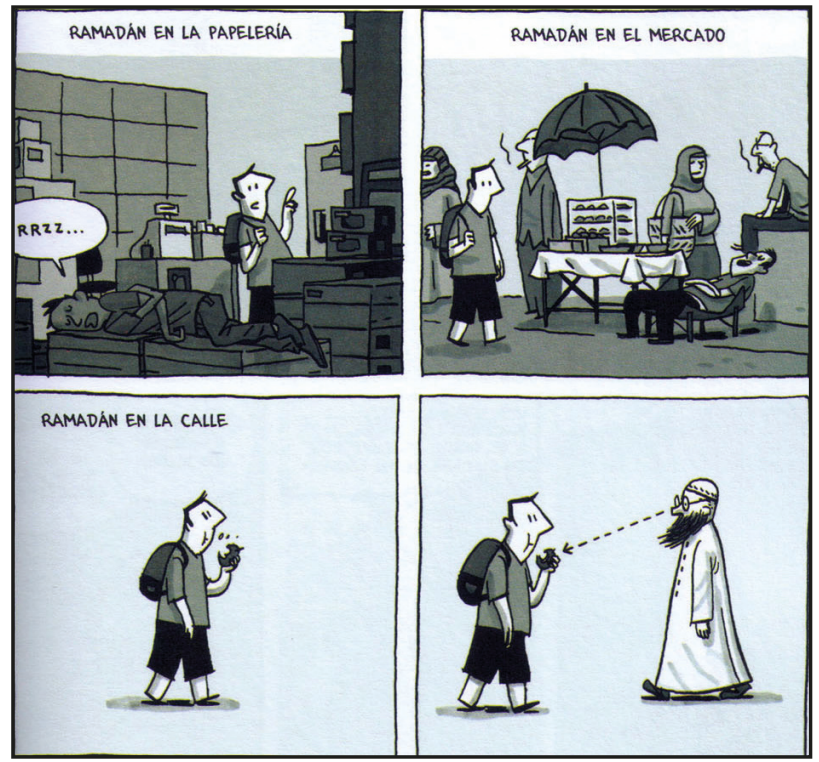

Fig. 2. El Ramadán según Delisle. 
La más inaccesible de todas las religiones con las que se encuentra Delisle es la musulmana. Y no nos referimos únicamente a las dificultades con las que se encuentra para poder visitar el mayor monumento cultural de origen musulmán que tiene la ciudad de Jerusalén: La explanada de las mezquitas. A lo largo del año, el autor descubre la brecha cultural que lo separa del mundo islámico en cuestiones iconográficas. Mientras el dibujante vive de la representación gráfica de la realidad, al mismo tiempo observa cómo este asunto puede llegar a agredir simbólicamente a la población musulmana. En este sentido, es bastante reveladora la escena en la que imparte una conferencia en la Universidad de Nablus. Durante ella y mientras expone algunas viñetas de su cómic Aline y los otros en los que aparecen unos desnudos, Delisle observa cómo se vacía un tercio de la sala.

En esta línea, también es especialmente paradigmático el encuentro que tiene el autor con una familia palestina que vive junto al muro de separación y con la que conversa acerca de las caricaturas de Mahoma publicadas por el periódico danés Jyllands-Posten. La reacción agresiva del padre de familia al hablar de estas coincide con la que se expandió por el mundo islámico los días posteriores a la publicación de dichas caricaturas. De esta manera, se evidencia la brecha existente entre la secularización de Occidente, sumido en un proceso de desimbolización, y el fanatismo creciente en algunos sectores de Oriente, agredido simbólicamente a través de unos dibujos (Bernete, 2007).

\subsection{El uso de fuentes y la construcción del relato}

La interpretación acerca del pasado y del presente en Crónicas de Jerusalén está determinada por las fuentes y los elementos que utiliza propios de la historiografía. Precisamente, en los momentos en los que el autor trata de aclarar en qué consiste el conflicto árabe-israelí es cuando más se evidencia esta tendencia. Aunque sin pretender jugar el papel de historiador, quizás sea entonces cuando más se acerque a un método de investigación científica. Para explicar temas como los asentamientos de colonias judías, la configuración del territorio israelí y palestino o el levantamiento del muro de separación acude a distintas fuentes como periodistas, psicólogos, trabajadores de la ONU, de Médicos Sin Fronteras y familias afectadas directamente por el conflicto. Esta labor, que sirve para aclarar la situación histórica de Israel y Palestina, se traduce en una serie de dibujos que ayudan gráficamente al lector a comprender mejor las diferentes posiciones.

Uno de los temas a los que presta mayor atención Delisle es la cuestión, tan controvertida, de los colonos (Fig. 3). De hecho, son varios los asentamientos que se nombran a lo largo del todo el cómic: Pisgat Ze'ev, Neve Yaakov y Sheikh Jarrah. Pero, además, estos son visitados por el autor y en cada uno de ellos intenta interactuar o comprender las distintas posturas ideológicas de las partes implicadas. A partir de su visita a estos, se pueden deducir los siguientes elementos que son de gran interés para comprender el conflicto. Lo primero es que las organizaciones humanitarias, como Médicos Sin Fronteras, se posicionan totalmente en contra de dichas colonias. Lo segundo es que sus medidas de seguridad y hermetismo evidencian una frágil 
situación de cara a la comunidad internacional, a la que se le ha dado la espalda y ante la que no se pueden justificar los asentamientos. Y lo tercero es que el movimiento ocupacional de los colonos tiene un alto componente de violencia.

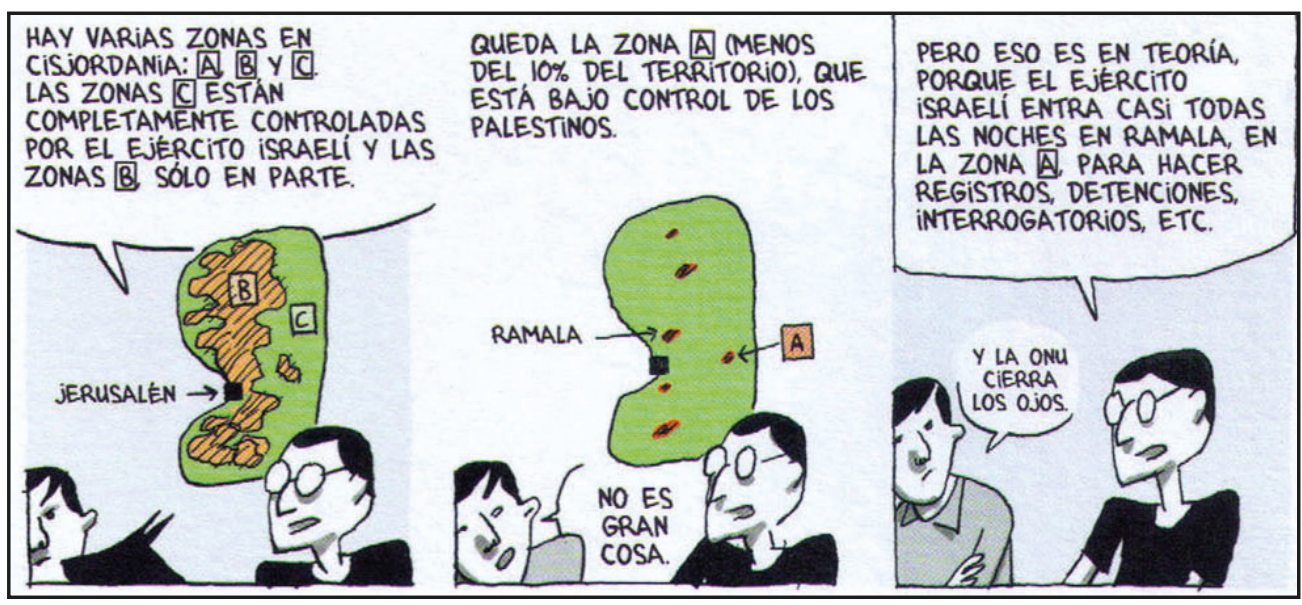

Fig. 3. Las zonas de Cisjordania.

Una de las colonia judías que más llama la atención en el cómic es la que está situada en la ciudad de Hebrón. Considerada como uno de los centros económicos y comerciales más relevantes de toda Cisjordania, esta ciudad, localizada a unos 37 kilómetros al sur de Jerusalén, ha sido uno de los principales objetivos de la colonización política y religiosa por parte del integrismo judío. Parte de la explicación puede hallarse en las reclamaciones que hacen tanto musulmanes como judíos de la Tumba de los Patriarcas, donde ambas religiones comparten raíces culturales.

No obstante, tras este trasfondo religioso, existen reivindicaciones claramente políticas, que responden a una estrategia por parte del gobierno israelí para pactar territorios en una futura negociación con las autoridades palestinas (Basallote Marín, 2009). En un intento por dar a conocer de forma objetiva el conflicto en Hebrón, Delisle realiza un ejercicio de imparcialidad: visitar la ciudad, por una parte, con una organización crítica con los asentamientos ("Breaking the Silence", creada por soldados veteranos para dar a conocer la situación de los territorios ocupados) y por otra, acompañado por los propios colonos, que los apoya.

De la visita a Hebrón por parte del autor de Crónicas de Jerusalén se desprenden dos acontecimientos que han marcado el conflicto de la ciudad. En primer lugar, la matanza que perpetuó el colono judío Baruch Goldstein tras asesinar a 29 palestinos en la Tumba de los Patriarcas en 1994. Y en segundo lugar, el atentado palestino que 1929 acabó con la vida de 67 judíos. Sin embargo, una de ellas siempre fue omitida en las dos visitas que realizó Delisle a Hebrón. Con la reconstrucción del pasado árabe-israelí que hace el dibujante, su discurso se acerca a la realidad histórica ya que adopta, por momentos, el papel de un investigador. No sólo nos cuenta los dos 
acontecimientos que trata de silenciar cada una de las partes del conflicto, sino que también denuncia el mismo acto de ocultar una parte de la Historia.

De su experiencia también rescata ciertos comentarios que hicieron sendos guías y que sirven para mostrar en qué medida difieren las versiones sobre estos acontecimientos históricos en particular. Por una parte, en la visita con "Breaking the Silence" se mantiene una actitud crítica con respecto al gobierno israelí y a los asentamientos, y se utiliza el derecho internacional para argumentar que estos son ilegales. Mientras que por otra parte, en la de los colonos, se emplean argumentos un tanto débiles como unos supuestos milagros religiosos que justificarían la presencia de judíos en Hebrón.

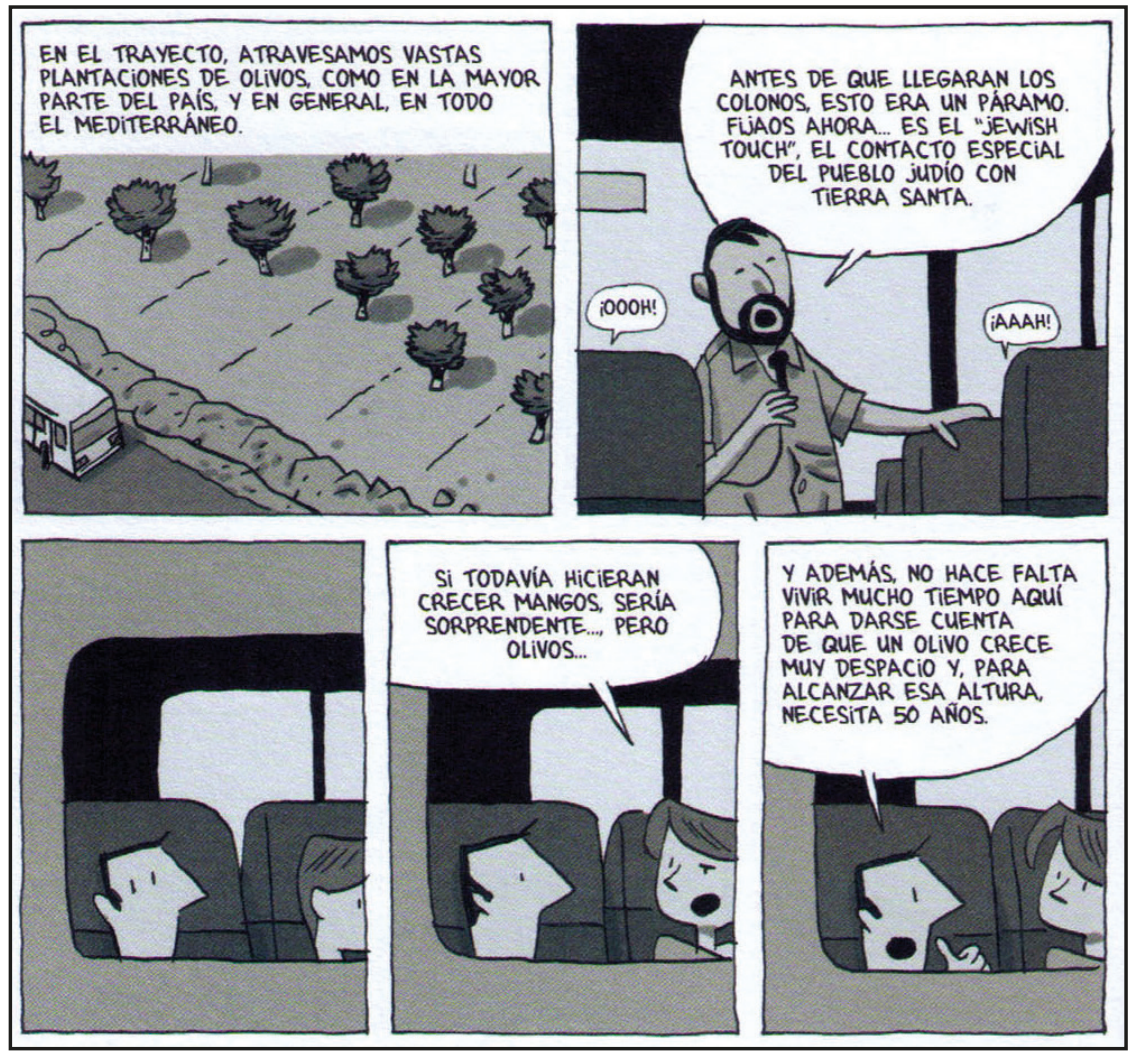

Fig. 4. Las razones que justifican la presencia de los colonos en tierras palestinas según el guía.

La estancia de Delisle en Jerusalén coincide con el conflicto que arrasó Gaza entre diciembre de 2008 y enero de 2009. Por este motivo, el cómic que estamos analizando puede servir a los historiadores como fuente para conocer cómo la denominada Operación 'Plomo Fundido' afectó, sobre todo, a organizaciones de ayuda humanitaria, y en este caso particular, a Médicos Sin Fronteras. A través de un seguimiento casi diario, el autor de Crónicas de Jerusalén plasma las noticias que va conociendo sobre el ataque de Israel: desde el número de víctimas, hasta los ataques aéreos, 
pasando por las reacciones de la comunidad internacional o de la prensa israelí. Entre sus viñetas caben la declaración de condena expresada por el Secretario General de la ONU, Ban Ki-Moon; las dificultades con las que se encontró Médicos Sin Frontera para enviar ayuda humanitaria a la Franja de Gaza; o el drama presenciado en directo en la televisión, cuando la casa del doctor Ezzeldeen Abu al-Aish, que estaba siendo entrevistado por la Cadena 10, sufrió un ataque de un obús, matando a tres de sus hijas (Fig. 5). Especialmente destacable es el testimonio de Cécile, trabajadora de Médicos Sin Fronteras que vivió los bombardeos de Gaza. Delisle dibuja la conversación con esta fuente primaria con el fin de reconstruir los hechos y evitar que el horror de la guerra caiga en el olvido.

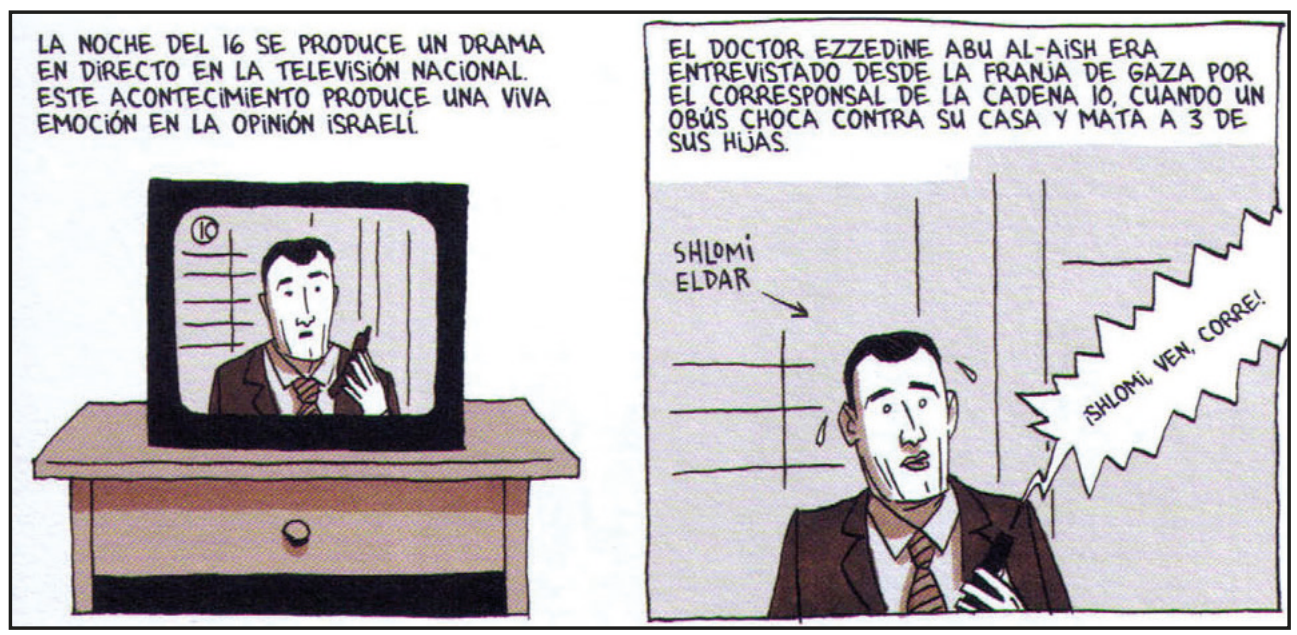

Fig. 5. Momento de la entrevista al doctor Ezzeldeen Abu al-Aish.

Más allá de los ataques que sufrieron los palestinos a manos de los israelíes en Gaza entre finales de 2008 y comienzos del 2009, el autor apenas comenta unos pocos incidentes violentos protagonizados por judíos. Destaca la noticia sobre un atentado sufrido por el fundador del movimiento "Paz Ahora", Zeev Sternhell, a manos de extremistas judíos. Según Delisle, la calificación de "atentado terrorista" que le otorga la prensa israelí contrasta con el tratamiento que se le pudiera dar desde Francia, por poner un ejemplo. Esta observación que hace el dibujante nos plantea cuestiones acerca de la manipulación mediática y el discurso hegemónico dominante del conflicto árabe-israelí en los medios europeos. De hecho, el cómic ofrece perspectivas que difícilmente se tendrían en la prensa oficial.

En cuanto al terrorismo palestino no hay apenas rastro en todo el cómic. Además del comentario que realiza sobre un atentado cometido por un palestino en Jerusalén mientras trabajaba en las obras del tranvía, destaca su visita a Balata, en Nablús. Allí descubre numerosos retratos de los que él llama "opositores más resistentes a la presencia israelí", de manera que se aleja de los términos "terroristas" y "mártires", 
utilizados, respectivamente, por israelíes y palestinos. De este modo, se consigue transmitir una posición de neutralidad frente al conflicto.

\subsection{La prospectiva del conflicto}

El cómic reúne una serie de características que lo hacen especialmente accesible y fácil de leer debido a la "plasticidad" (Rubenstein, 2004). Por eso, es fácil comprender cuestiones que son difíciles de explicar de manera sintética. A juicio del dibujante el verdadero conflicto se encuentra en los controles del ejército israelí, en el muro de separación y en las barreras, en general (Fig. 6), que dificultan la movilidad de los palestinos dentro de su territorio. Estremecedora es su explicación gráfica sobre el paso del control de Qalandia, que él mismo experimenta y que es capaz de sintetizar en unas pocas viñetas.

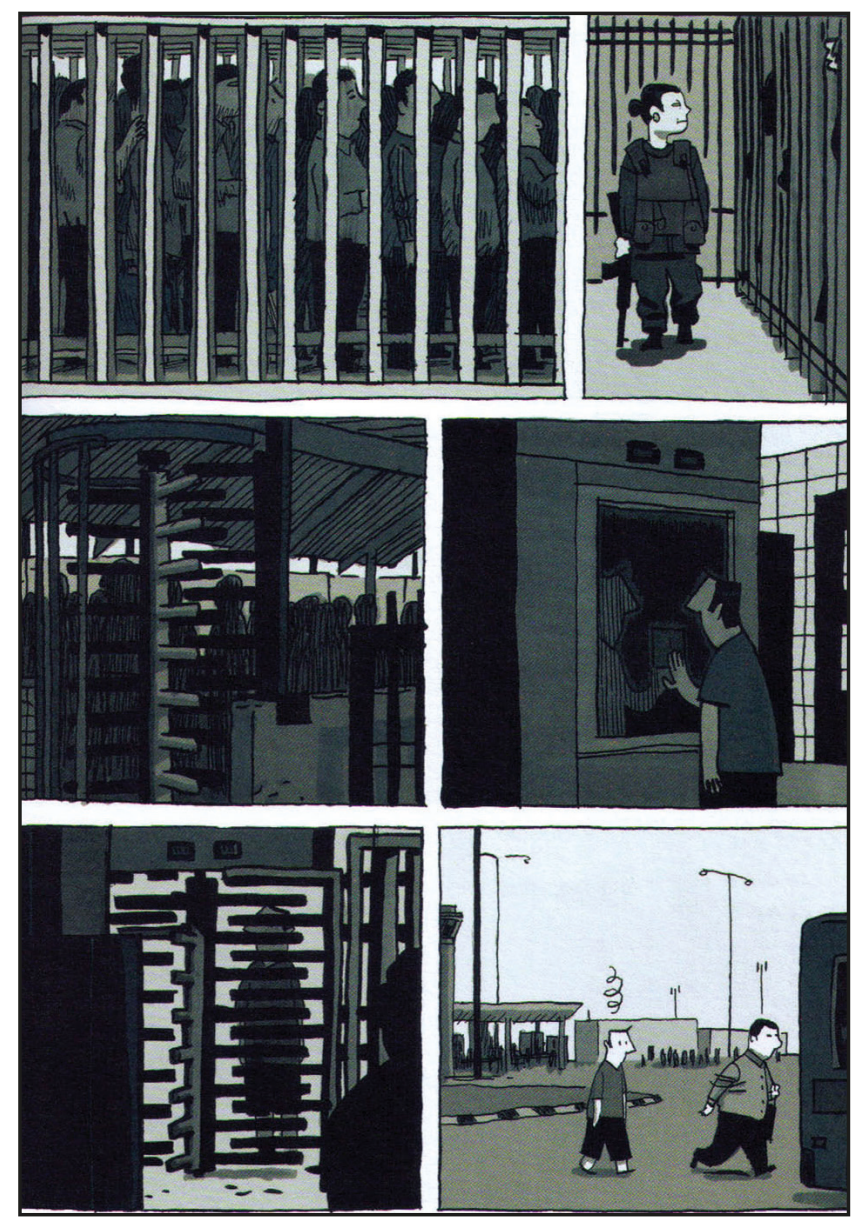

Fig. 6. El paso de Qalandia. 
Pero los controles no sólo afectan a la población árabe, sino también a los propios extranjeros como Delisle. Para entrar en el país, como así pudo comprobar el autor en dos ocasiones, el personal de la compañía aérea El-Al obliga a realizar un interminable cuestionario por motivos de seguridad. Aparte de los numerosos checkpoints que se distribuyen por todo el territorio de Cisjordania, quizás sea el control de la Franja de Gaza el que mejor represente la situación que viven los palestinos en su tierra. Sin embargo, al no poseer autorización para cruzar el paso de Eraz, Delisle no nos deja ilustraciones al respecto.

Muchas de las propuestas que hay sobre la mesa para acabar con el problema palestino-israelí no hacen sino prolongar el conflicto. Sin embargo, en el fondo de la cuestión se encuentran temas como el Estado de Palestina, el estatus de Jerusalén, los refugiados o las colonias, que no acaban de situarse como prioritarios en la agenda política (Bosemberg, 2009). A lo largo del texto Crónicas de Jerusalén, su autor no aporta soluciones, sin embargo, deja entrever que existen ciertos vínculos que pueden servir como punto de partida para una futura reconciliación. Delisle se apoya en las investigaciones del historiador israelí Tom Segev para recordar cuáles fueron las reacciones de la población árabe ante el atentado del 29, comentado anteriormente, las cuales evidenciaban la cooperación que entonces unía a judíos y árabes.

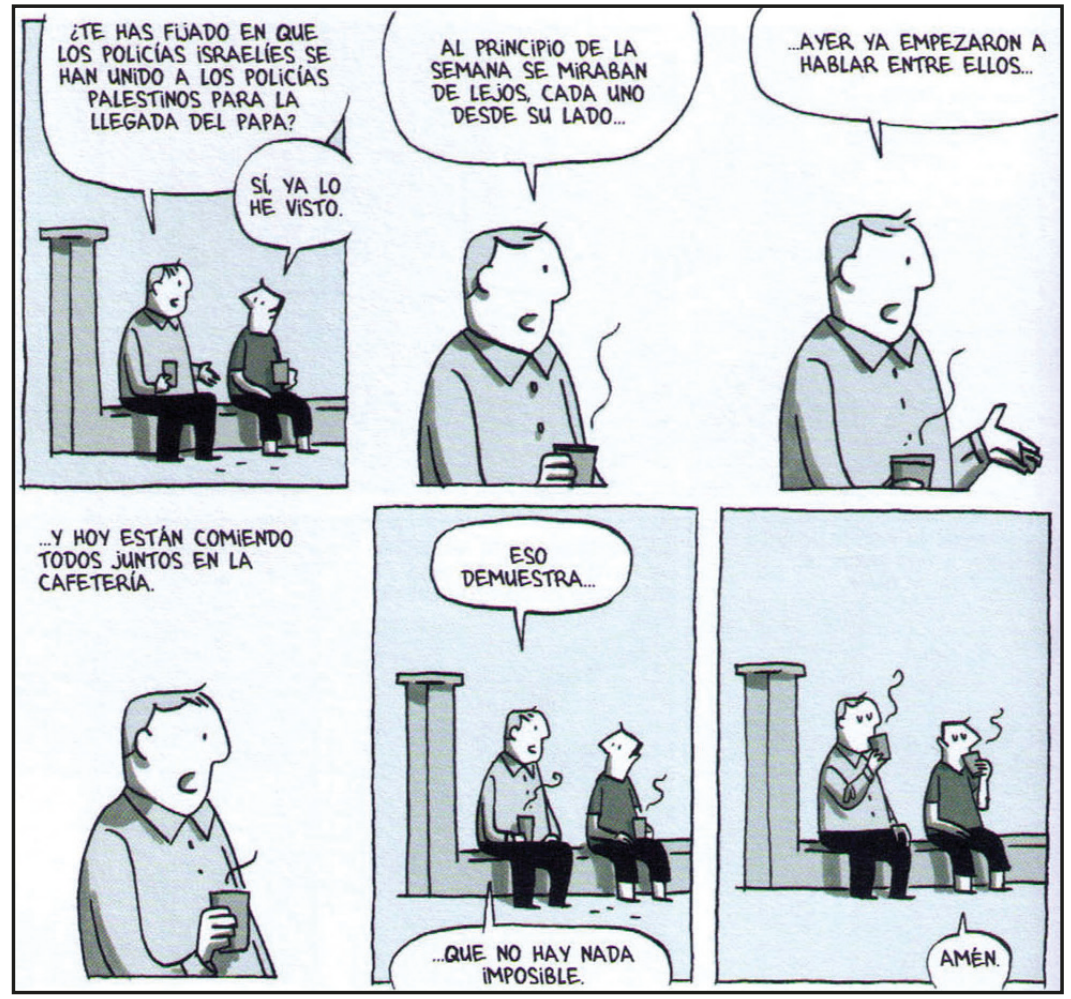

Fig. 7. Colaboración israelí-palestina por la visita del Papa. 
A este respecto, también nos descubre ciertas prácticas sociales que muestran un ambiente pacífico cuando mujeres judías ortodoxas, mujeres judías laicas y mujeres musulmanas se reúnen en un parque a cuidar de sus hijos. Por último, destaca la colaboración de policías israelíes y policías palestinos durante la visita del papa Benedicto XVI a Jerusalén (Fig. 7), como muestras de que el diálogo y la convivencia son posibles. En este sentido, el cómic no sólo pretende entretener, sino también enseñar (Eisner, 2008), pues tiene marcados fines didácticos.

\section{Conclusiones}

No ha sido hasta la segunda mitad del siglo XX cuando se han incorporado al estudio de la Historia fuentes derivadas del cine o la fotografía. Es en este contexto en el que tenemos que comenzar a considerar las artes gráficas y, entre ellas, el cómic, como una fuente válida para el campo de la investigación histórica, ya que estas, de manera análoga a otros subgéneros como el documental histórico, son en sí mismas una fuente histórica. Es más, tienen la capacidad de transmitir a sus lectores una visión particular del suceso, conflicto o acontecer histórico (Burke, 2001). A lo largo del presente artículo hemos tratado de demostrar la utilidad del cómic Crónicas de Jerusalén de Guy Delisle para el estudio del conflicto árabe-israelí. A pesar de las limitaciones que podría presentar esta obra como fuente histórica, existen ciertos puntos clave que hemos de tener en consideración y que nos permiten afirmar que esta obra gráfica es una fuente válida para la investigación histórica.

En primer lugar, el aporte de datos y elementos mostrados en este cómic permiten explicar el conflicto bélico desde una perspectiva global. En segundo lugar, el distanciamiento ideológico y religioso mostrado por Delisle frente al conflicto, evidencian su pretensión de neutralidad, ejerciendo, en cierta medida, el rol de un historiador. En tercer lugar, la utilización de fuentes primarias, centradas sobre todo en el testimonio de actores que participan en el conflicto para la construcción de su discurso, muestra su afán por mostrar a todos los implicados en el mismo. En cuarto lugar, la simplicidad propia del formato del cómic y la capacidad del autor por captar lo relevante y expresar lo importante, dan buena muestra de sus fines didácticos y su carácter prospectivo. En definitiva, nos encontramos ante un relato gráfico, rico en interpretaciones y gracias al cual se pueden conocer nuevas perspectivas sobre este tema. Todo ello es una muestra de que este tipo de fuentes son interesantes y pueden complementar una investigación científica sobre un conflicto bélico, tan histórico como actual, como es el de Israel-Palestina. 


\section{Referencias bibliográficas}

ABELLO, J. (2001). "El conflicto armado como espectáculo del infoentretenimiento". En BONILLA, J. y PATIÑO, G. (eds.) (2001). Comunicación y política. Viejos conflictos, nuevos desafios. Bogotá: Centro Editorial Javeriano. p. 412-420.

ALBARRÁN DE ALBA, G. (1999). "Colombia, Perú, Brasil, México... Latinoamérica: periodismo y muerte". En: Sala de Prensa, año 1, vol. 1. En línea: http:// www.saladeprensa.org/art05.htm

ALÍA MIRANDA, F. (1998). Técnicas de investigación para historiadores. Las fuentes de la Historia. Madrid: Síntesis.

ÁLVAREZ-OSSORIO ALVARIÑO, I. (2006). "El lenguaje religioso en el conflicto israelo-palestino". En DE LA PUENTE, C. y SERRANO, D. (eds.) (2006). Activismo político y religioso en el mundo islámico contemporáneo. Madrid: Siglo XXI Editores. p. 85-103.

ANKERSMIT, F. R. (2002). Historical Representation. California: Stanford University Press.

BARBIERI, D. (1993). Los lenguajes del cómic. Barcelona: Paidós.

BARÓN, L. F. y VALENCIA, M. (2001). "Medios, audiencias y conflicto armado. Representaciones sociales en comunidades de interpretación y medios informativos". En: Controversia, no 178, Bogotá: CINEP/PPP. p. 43-81.

BASALLOTE MARÍN, A. (2009). "Hebrón, la otra Jerusalén". En: Revista de Estudios Internacionales Mediterráneos, $\mathrm{n}^{\circ}$ 8, Madrid: Taller de Estudios Internacionales Mediterráneos de la Universidad Autónoma de Madrid. p. 27-46.

BAUDRILLARD, J. (1984). Cultura y simulacro. Barcelona: Editorial Kairós.

BERNETE, F. (2007). "Lecturas y usos de las viñetas sobre el Islam". En: Trama y fondo. Revista de Cultura, $\mathrm{n}^{\circ}$ 22, Segovia: Asociación Cultural Trama y Fondo. p. 57-66.

BONILLA, J. I. y TAMAYO, C. A. (2007). "Violencias y medios de comunicación en América Latina: una cartografía para el análisis". En: Signo y Pensamiento, vol. 26, $\mathrm{n}^{\circ}$ 50, Bogotá: Facultad de Comunicación y Lenguaje de la Pontificia Universidad Javeriana. p. 212- 231.

BOSEMBERG, L. E. (2009). "El conflicto palestino-israelí. Una propuesta para la negociación". En: Colombia Internacional, n 69, Bogotá: Departamento de Ciencia Política de la Universidad de los Andes. p. 142-161.

BURKE, P. (2001). Visto y no visto: uso de la imagen como documento histórico. Barcelona: Crítica.

CUÑARRO, L., y FINOL, J. (2012). "Semiótica del cómic civil war como expresión simbólica de la realidad social e histórica de los estados unidos luego del 9/11". En: Revista S, Bucaramanga: Escuela de Idiomas de la Universidad Industrial de Santander, vol. 5, $\mathrm{n}^{\mathrm{o}}$ 1. En línea: http://revistas.uis.edu.co/index.php/revistaS/ article/view/2934

DA SILVA, K. Ch. (2012). "El cómic y sus relaciones con la Historia: un estudio de las representaciones del 11 de septiembre de 2001 y sus consecuencias". En: Segundo Congreso Internacional Viñetas Serias. Narrativas Gráficas: Lenguajes entre el Arte y el Mercado, Buenos Aires. 
DANTO, A. (1989). Historia y narración. Barcelona: Paidós.

DEBORD, G. (2002). La sociedad del espectáculo. Valencia: Pre-textos.

DEL RÍO, E. (1984). La vida de cuadritos: Guía incompleta de la historieta. México: Grijalbo.

DELISLE, G. (2011). Crónicas de Jerusalén. Bilbao: Astiberri Ediciones.

ECO, U. (1990). Apocalípticos e integrados. Barcelona: Lumen.

EISNER, W. (2008). Comic and sequential art. Principles and practices from the legendary cartoonist. New York: W.W. Norton \& Company.

FERNÁNDEZ L'HOESTE, H. y POBLETE, J. (eds.) (2009). Redrawing the Nation: National Identity in Latin/o American Comics. New York: Palgrave Macmillan.

FERNÁNDEZ SERRATO, J. C. (2004). "El capitán América nunca supo convencer a los malos. Leyendo en los cómics más allá de la adolescencia". En CONTRERAS, F. y SIERRA, F. (coords.) (2004). Culturas de guerra. Medios de información y violencia simbólica. Madrid: Cátedra. p. 187-224.

FERRO, M. (1980). Cine e Historia. Barcelona: Editorial Gustavo Gili.

FLORES, E. Ch. (2007). "Dos feitos a dos ditos: História e Cultura Histórica". En: Saeculum. Revista de História, año 13, $\mathrm{n}^{\mathrm{O}}$ 16, Joao Pessoa: Departamento de História da UFPB. p. 83-102.

GASCA, L. y GUBERN, R. (1991). El discurso del cómic. Madrid: Cátedra.

GLIDDEN, S. (2011). Una judia americana perdida en Israel. Barcelona: Norma Editorial.

GUAL BORONAT, O. (2011). "El cómic como fuente histórica: el falso testimonio de Tintín en el congo Belga". En: Espacio, Tiempo y Forma, Serie V, Historia Contemporánea, $\mathrm{n}^{\circ}$ 23, Madrid: Universidad de Educación a Distancia. p. 141-158.

GUBERN, R. (1974). El lenguaje de los cómics. Barcelona: Península.

GUTIÉRREZ PÁRRAGA, T. (2006). "El cómic en los adolescentes. Estudio y práctica en el aula. Una propuesta de evaluación". En: Arte, Individuo y Sociedad, no 18, Madrid: Servicio de Publicaciones Universidad Complutense de Madrid. p. 29-56.

HANUKA, A. (2013). KO en Tel Aviv. Tarragona: Ponent Mon.http://www.apostadigital.com/revistav3/hemeroteca/pvdiaz.pdf

LE ROY, M. (2011). Saltar el muro. Turín: 001 Ediciones.

MAHECHA, N. (2012). "De lo distractivo a lo instructivo. Algunas aproximaciones al uso de la historieta histórica en la enseñanza de la historia". En: Praxis Pedagógica, $\mathrm{n}^{\mathrm{o}}$ 13, Bogotá: Facultad de Educación de la Corporación Universitaria Minuto de Dios. p. 166-191.

MASOTTA, O. (1982). La historieta en el mundo moderno. Barcelona: Paidós.

MELERO DOMINGO, J. (2012). "Footnotes in Gaza. El cómic-reportaje como género periodístico". En: Estudios sobre el mensaje periodístico, vol. 18, n 2 , Madrid: Servicio de Publicaciones de la Universidad Complutense. p. 541-561.

MONTANARI, F. (2000). "Guerra y comunicación". En: Revista de Occidente, $\mathrm{n}^{\mathrm{o}}$ 232, Madrid: ARCE. p. 46-59. 
ORDÓÑEZ DÍAZ, L. (2008). "Historia, literatura y narración". En: Historia Crítica, $\mathrm{n}^{\circ}$ 36, Bogotá: Departamento de Historia de la Universidad de los Andes. p. 194-222.

PEREIRA, J. M. y GARCÍA RAYA, M. E. (2000). "Comunicación, universidad y cultura de paz". En: Diálogos de la Comunicación, n 59-60, Cali: FELAFACS. p. 67-74.

PIZARROSO QUINTERO, A. (2004). "Guerra y comunicación. Propaganda, desinformación y guerra psicológica en los conflictos armados". En CONTRERAS, F. y SIERRA, F. (coords.) (2004). Culturas de guerra. Medios de información y violencia simbólica. Madrid: Cátedra. p. 17-56.

PORTILLA GÓMEZ, J. M. (2007). "La Corte Internacional de Justicia frente al conflicto palestino-israelí". En: Revista Facultad de Derecho y Ciencias Políticas, vol. 37, $\mathrm{n}^{\circ}$ 106, Medellín: Escuela de Derecho y Ciencias Políticas de la Universidad Pontificia Bolivariana. p. 155-179.

RICOEUR, P. (1999). Historia y narratividad. Buenos Aires: Paidós.

RICOEUR, P. (2007). Tiempo y narración. Configuración del tiempo en el relato histórico. Madrid: Siglo XXI Editores.

ROSENSTONE, R. A. (1988). "La historia en imágenes / La historia en palabras". En: The American Historical Review, vol. 93, n 5, Bloomington: American Historical Association. p. 1173-1185.

RUBENSTEIN, A. (2004). Del Pepín a Los Agachados. Cómics y censura en el México posrevolucionario. México: Fondo de Cultura Económica.

SACCO, J. (2010). Notas al pie de Gaza. Barcelona: Mondadori.

TOSELLLI, C. (2006). "Algunas reflexiones sobre el turismo cultural". En: PASOS. Revista de Turismo y Patrimonio Cultural, vol. $4, \mathrm{n}^{\circ}$ 2, La Laguna: Laboratorio de Antropología Social de la Universidad de La Laguna. p. 175-182.

VERGARA DÍAZ, P. (2009). "El cómic en España: 1977-2007”. En: Aposta. Revista de Ciencias Sociales, $\mathrm{n}^{\circ}$ 42, En línea:

VEYNE, P. (1984). Cómo se escribe la Historia. Foucault revoluciona la Historia. Madrid: Alianza.

VICH, S. (1997). La historia en los cómics, Barcelona: Editorial Glenat.

VILAR, M $M^{\mathrm{a}}$ J. (2003). "Una percepción desde España de la cuestión Palestina. Aproximación a sus fuentes documentales y bibliográficas en español". En: Anales de Historia Contemporánea, $\mathrm{n}^{\circ}$ 19, Murcia: Servicio de Publicaciones de la Universidad de Murcia. p. 285-325.

WHITE, H. (1992). Metahistoria. La imaginación histórica en la Europa del siglo $X I X$. México: Fondo de Cultura Económica.

WITEK, J. (1989). Comic Books as History: The Narrative Art of Jack Jackson, Art Spiegelman, and Harvey Pekar. Jackson: University Press of Mississippi.

YAKIN, B. y BERTOZZI, N. (2013). Jerusalén. Un retrato de familia. Barcelona: Ediciones La Cúpula.

YANN y JUILLARD, A. (2013). Mezek. Barcelona: Norma Editorial. 


\section{Los autores}

Salomé Sola Morales es Doctora en Medios, Comunicación y Cultura por la Universidad Autónoma de Barcelona; Magíster en Ciencias de la Comunicación por la UAB y Licenciada en Comunicación Audiovisual por la Universidad de Sevilla, España. Ha trabajado como investigadora y docente de grados y posgrados en la Facultad de Comunicación de la Universidad Autónoma de Barcelona desde 2008 hasta 2013 y en la Universidad Internacional de Cataluña. Desde 2013 es Associate Professor en la Escuela de Periodismo de la Universidad de Santiago de Chile, donde imparte las cátedras de Teoría de la Comunicación IV y Seminario de Título 1 y 2. Actualmente es Investigadora principal en el Proyecto DICYT "Participación de los jóvenes chilenos en la vida democrática. Impacto de los nuevos medios de comunicación" y co-investigadora del equipo chileno de The World of Journalism Study de la University of Munich y del proyecto Journalism Students around the Globe de la Universidad de Santiago de Chile. Autora de numerosos artículos y ensayos científicos en revistas indexadas, sus áreas de investigación principales son la antropología de la comunicación, las teorías sobre narrativa e identidad, y los estudios de recepción, participación política y juventud.

Gonzalo Barroso Peña es Magíster en Métodos y Técnicas Avanzadas de Investigación Histórica por la Universidad Nacional de Educación a Distancia (UNED). Entre 2008 y 2009 obtuvo la Licenciatura en Historia y la Licenciatura en Comunicación Audiovisual por la Universidad de Sevilla. Se ha desempeñado como Profesor de Historia en distintos centros educativos de Barcelona (C. E. Dolmen y Oak House School). Actualmente, trabaja como Coordinador Académico y Docente en el Diplomado en Guión de Documental Histórico por la Universidad Finis Terrae (Chile). Además, es Investigador ayudante en el equipo chileno para The Worlds of Journalism Study de la Universidad de Munich. Sus principales líneas de investigación son: la metodología histórica, la Historia contemporánea y el vínculo entre medios audiovisuales e Historia. 